\title{
Testing avian, squamate, and mammalian nuclear markers for cross amplification in turtles
}

\author{
Phillip Q. Spinks • Robert C. Thomson • \\ Anthony J. Barley - Catherine E. Newman • \\ H. Bradley Shaffer
}

Received: 29 September 2009/ Accepted: 21 January 2010/Published online: 5 February 2010

(C) The Author(s) 2010. This article is published with open access at Springerlink.com

\begin{abstract}
We used PCR amplifications to assess 120 previously described nuclear markers for phylogeographic and phylogenetic analysis in turtles. Twenty-seven of 120 markers amplified a single PCR product for both the western pond turtle (Emys marmorata) and the West African mud turtle (Pelusios castaneus), 71 amplified a single product in either E. marmorata or P. castaneus, and a subset of eight markers amplified single products across a test panel of 11 additional turtle species representing a broad sample of turtle diversity. Our ongoing research shows that nuclear markers developed for birds, squamates, and other vertebrate taxa can be useful for analyses of turtles, suggesting that many primers are transferable across large phylogenetic distances.
\end{abstract}

Keywords Intron - Nuclear loci $\cdot$ Primers $\cdot$ Testudines

Electronic supplementary material The online version of this article (doi:10.1007/s12686-010-9184-7) contains supplementary material, which is available to authorized users.

P. Q. Spinks $(\square)$ - R. C. Thomson · A. J. Barley ·

C. E. Newman · H. Bradley Shaffer

Department of Evolution and Ecology, University of California,

Davis, CA 95616, USA

e-mail: pqspinks@ucdavis.edu

P. Q. Spinks · R. C. Thomson · H. Bradley Shaffer Center for Population Biology, University of California, Davis, CA 95616, USA

Present Address:

A. J. Barley

Department of Ecology and Evolutionary Biology,

University of Kansas, Lawrence, KS 66045, USA
The need for multi-marker analysis in phylogenetic and phylogeographic studies is now well recognized and methods for developing these marker resources are undergoing an increase in research effort. Genomic resources are increasingly being used to develop large numbers of markers for their specific clades (e.g. Backström et al. 2008; Li et al. 2007; Thomson et al. 2008; Townsend et al. 2008), but the extent to which these markers cross-amplify in more distantly related taxa is poorly characterized. If markers that are developed in one clade can be widely used in related lineages then a very simple and inexpensive strategy for marker development is to cross-amplify these markers, thereby avoiding the cost and time associated with developing novel, clade-specific resources. Such a strategy clearly can work at somewhat lower taxonomic levels, as demonstrated by the considerable success of primers developed in a single species across turtles (Thomson et al. 2008). Recent marker development projects have produced a relatively large number of nuclear primers for birds, mammals and squamate reptiles (Backström et al. 2008; Berlin et al. 2008; Kimball et al. 2009; Murphy et al. 2001; Townsend et al. 2008) and are a potential source of nuclear markers for other vertebrate taxa. For example, previous work on a small number of markers developed for birds demonstrated that such markers can be useful for phytogeographic and phylogenetic analyses of turtles (Noonan and Chippindale 2006; Spinks and Shaffer 2007, 2009; Spinks et al. 2009a, b). Here, we assessed 120 currently available nuclear markers from the literature that were originally developed for birds, mammals, and squamate reptiles for use in phylogeography and phylogenetic analyses of turtles.

We assembled a set of 120 single copy nuclear markers from the sources listed above as well as from Armstrong et al. (2001), Chubb (2004), Dolman and Phillips (2004), 
Friesen et al. (1999), Handley et al. (2004), Lyons et al. (1997), Primmer et al. (2002), Prychitko and Moore (1997), and Sehgal and Lovette (2003), and screened these markers using a two-pronged strategy. First, we performed PCR reactions in a gradient thermocycler (Peltier PTC-200) using AmpliTaq mediated $20 \mu \mathrm{L}$ reactions. Cycling conditions were an initial denaturation of $60 \mathrm{~s}$ at $95^{\circ} \mathrm{C}$, followed by 38 cycles of denaturation $\left(94^{\circ} \mathrm{C}\right.$ for $\left.30 \mathrm{~s}\right)$, annealing ( $45 \mathrm{~s}$ at $\left.55^{\circ}-65^{\circ} \mathrm{C}\right)$, and extension $\left(72^{\circ} \mathrm{C}\right.$ for $\left.60 \mathrm{~s}\right)$ with a final extension period $\left(72^{\circ} \mathrm{C}\right.$ for $\left.10 \mathrm{~min}\right)$. For this initial screen, we used DNA template from two species that span the root node of turtles: the western pond turtle (Emys marmorata), a cryptodire from western North America, and the West African mud turtle (Pelusios castaneus), a pleurodire from west Africa. Each PCR reaction was scored on a 1\% agarose gel as producing a single band, multiple bands, a smear or no visible product (Online Resource 1).

Of the 120 markers, 49 did not amplify (no product or only smears) or amplified multiple bands, and were not considered further. The remaining 71 markers produced a single band in either E. marmorata or $P$. castaneus and, of these, 27 produced a single band in the initial PCR reactions for both species. Next, we eliminated three markers that had a predicted size of less than 400 base pairs (bp), leaving 68 markers that produced a single band (25 of which amplified in both species) for further evaluation (Online Resource 1). We further tested these 68 markers by performing PCR reactions on a test panel of 11 additional turtle species representing a broad phylogenetic sampling of turtle diversity (Fig. 1, Online Resource 1). For these reactions, we used the same PCR cycling conditions as previously described, but used the optimal annealing temperature/locus identified in the initial gradient reactions for each marker (Online Resource 1).
Thirteen of the 68 markers worked well across the panel including eight that successfully amplified across all species, one that amplified for $12 / 13$ species, and four that amplified for 11/13 species. On the other hand, 15 markers amplified a single band for a single species only (Fig. 1). Overall, each of the 68 markers worked in an average of 3.7 turtle species, but there was a high variance in this measure (Standard deviation $=4.3$ ). A somewhat surprising result was the lack of correlation between phylogenetic relationships and marker success. For example, among our test panel (Fig. 1), the painted turtle (Chrysemys picta) is more closely related to $E$. marmorata (one of the species we used for optimization) than any other species (Barley et al. in press), yet only 15/68 markers amplified a single band for $C$. picta while 29 markers successfully amplified for the more distantly related green sea turtle (Chelonia mydas; Fig. 1); based on phylogenetic relationships, we would have expected the opposite pattern.

There may be additional opportunities to further develop turtle primers from our panel of 68 markers. Our initial PCR amplifications were gradient reactions composed of twelve PCR reactions/marker for one E. marmorata and one $P$. castaneus while the secondary assessments (i.e. those across the remaining 11 species in the turtle diversity panel) were performed using one PCR reaction/marker/species and a single annealing temperature. For example, in cases where a marker amplified for E. marmorata, but not $P$. castaneus, we used the optimal temperature identified for E. marmorata in subsequent PCR reactions across the 11-species panel; when only $P$. castaneus worked, we used its optimal temperature. In cases where a marker amplified for both E.marmorata and $P$. castaneus, we used the midpoint temperature between both species (Online Resource 1). Researchers who further experiment with each species/marker combination using a

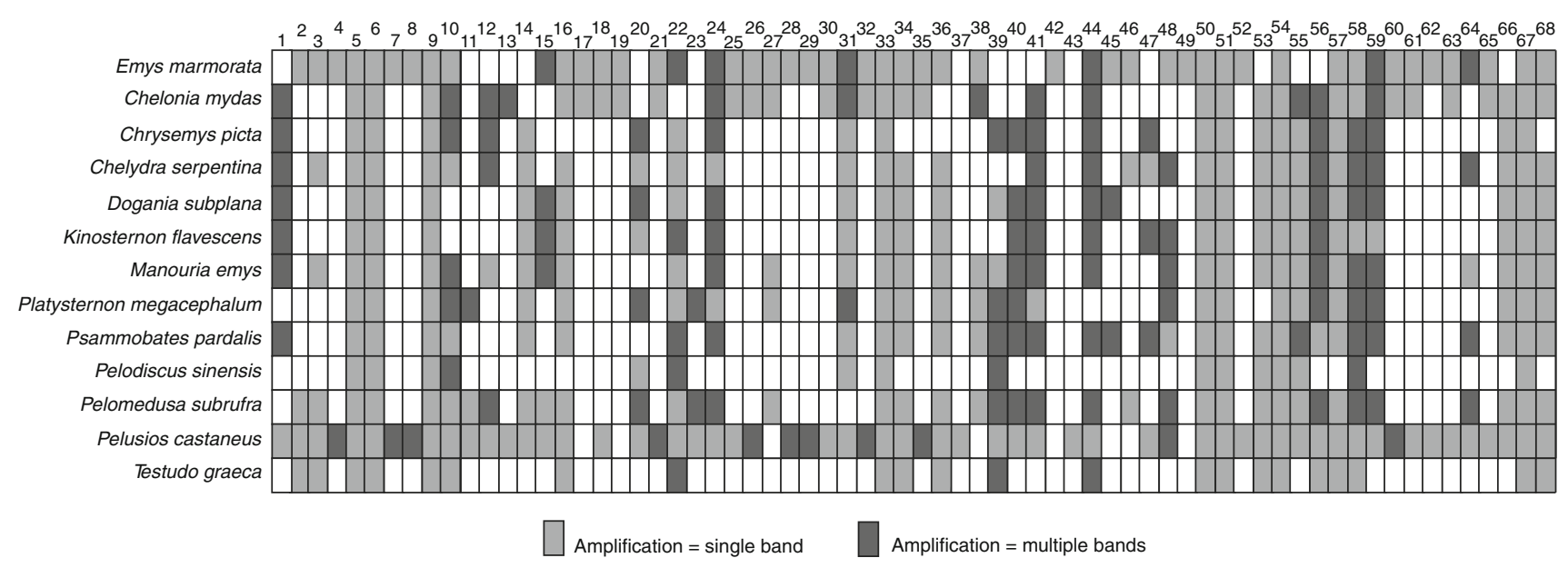

Fig. 1 Results of PCR reactions of 68 loci for 13 turtle species. Gray cells indicate reactions that produced a single band. Black cells indicate multiple bands or smears while white cells indicate no product. Marker numbers correspond to those in Online Resource 1 
gradient approach will probably increase the number of successful single-product PCR reactions/species due to the increased number of reaction conditions for each species/ marker combination.

Previous work unequivocally shows that genomic resources are a rich resource for novel molecular markers in non-model organisms, and these marker resources are often useful outside of the clade in which they were designed. For example, the eight markers that worked across all species considered here were sequenced and used for a phylogenetic analysis of turtles (Barley et al. in press) resulting in a wellsupported phylogeny. Our past and ongoing sequencing efforts suggest that, in general, markers that amplify single bands also produce clean sequence data that is phylogenetically informative (Barley et al. in press; Thomson et al. 2008). Thus, cross-amplification of existing marker resources appears to be an efficient way to identify markers for phylogenetic and phylogeography studies. This strategy has provided a large number of new nuclear markers for use in turtle phylogenetics and phylogeography, and should be a fruitful approach for other taxa.

Acknowledgments We thank Carla Cicero (Museum of Vertebrate Zoology), Kevin de Queiroz (United States National Museum of Natural History), Jens Vindum (California Academy of Sciences), and Dan Holland for providing tissues for this study. This research was supported by grants from the National Science Foundation (DEB0817042), and California Department of Fish and Game (HBSDF15) and the UC Davis Agricultural Experiment Station.

Open Access This article is distributed under the terms of the Creative Commons Attribution Noncommercial License which permits any noncommercial use, distribution, and reproduction in any medium, provided the original author(s) and source are credited.

\section{References}

Armstrong MH, Braun EL, Kimball RT (2001) Phylogenetic utility of avian ovomucoid intron G: a comparison of nuclear and mitochondrial phylogenies in Galliformes. Auk 118:799-804

Backström N, Fagerberg S, Ellegren H (2008) Genomics of natural bird populations: a gene-based set of reference markers evenly spread across the avian genome. Mol Ecol 17:964-980

Barley AJ, Spinks PQ, Thomson RC, Shaffer HB (in press) Fourteen nuclear genes provide phylogenetic resolution for difficult nodes in the turtle tree of life. Mol Phylogen Evol. doi:10.1016/j.ympev. 2009.11.005

Berlin S, Quintela M, Höglund J (2008) A multilocus assay reveals high nucleotide diversity and limited differentiation among Scandinavian willow grouse (Lagopus lagopus). BMC Genetics 9:89
Chubb AL (2004) New nuclear evidence for the oldest divergence among neognath birds: the phylogenetic utility of ZENK. Mol Phylogen Evol 30:140-151

Dolman G, Phillips B (2004) Single copy nuclear DNA markers characterized for comparative phylogeography in Australian wet tropics rainforest skinks. Mol Ecol Notes 4:185-187

Friesen VL, Congdon BC, Kidd MG, Birt TP (1999) Polymerase chain reaction (PCR) primers for the amplification of five nuclear introns in vertebrates. Mol Ecol Notes 8:2141-2152

Handley LJL, Ceplitis H, Ellegren H (2004) Evolutionary strata on the chicken $\mathrm{Z}$ chromosome: implications for sex chromosome evolution. Genetics 167:367-376

Kimball RT, Braun EL, Barker FK et al (2009) A well-tested set of primers to amplify regions spread across the avian genome. Mol Phylogen Evol 30:654-660

Li C, Ortí G, Zhang G, Lu G (2007) A practical approach to phylogenomics: the phylogeny of ray-finned fish (Actinopterygii) as a case study. BMC Evol Biol 7:44

Lyons LA, Laughlin TF, Copeland NG et al (1997) Comparative anchor tagged sequences (CATS) for integrative mapping of mammalian genomes. Nat Genet 15:47-56

Murphy WJ, Eizirik E, Johnson WE et al (2001) Molecular phylogenetics and the origins of placental mammals. Nature 409:614-618

Noonan BP, Chippindale PT (2006) Vicariant origin of Malagasy reptiles supports late cretaceous Antarctic land bridge. Am Nat 168:730-741

Primmer CR, Borge T, Lindell J, Saetre GP (2002) Single-nucleotide polymorphism characterization in species with limited available sequence information: high nucleotide diversity revealed in the avian genome. Mol Ecol 11:603-611

Prychitko TM, Moore WS (1997) The utility of DNA sequences of an intron from the b-fibrinogen gene in phylogenetic analysis of woodpeckers (Aves: Picidae). Mol Phylogen Evol 8:193-204

Sehgal RNM, Lovette IJ (2003) Molecular evolution of three avian neurotrophin genes: implications for proregion functional constraints. J Mol Evol 57:335-342

Spinks PQ, Shaffer HB (2007) Conservation phylogenetics of the Asian box turtles (Geoemydidae, Cuora): mitochondrial introgression, numts, and inferences from multiple loci. Cons Genet 8:641-657

Spinks PQ, Shaffer HB (2009) Conflicting mitochondrial and nuclear phylogenies for the widely disjunct Emys (Testudines: Emydidae) species complex, and what they tell us about biogeography and hybridization. Syst Biol 58:1-20

Spinks PQ, Thomson RC, Lovely GA, Shaffer HB (2009) Assessing what is needed to resolve a molecular phylogeny: simulations and empirical data from emydid turtles. BMC Evol Biol 9:56

Thomson RC, Shedlock AM, Edwards SV, Shaffer HB (2008) Developing markers for multilocus phylogenetics in non-model organisms: a test case with turtles. Mol Phylogen Evol 49:514-525

Townsend TM, Alegre RE, Kelley ST, Weins JJ, Reeder TW (2008) Rapid development of multiple nuclear loci for phylogenetic analysis using genomic resources: an example from squamate reptiles. Mol Phylogen Evol 47:129-142 